\title{
Clinical Significance of Conventional Rib Series in Patients with Minor Thoracic Trauma
}

\section{Klinische Signifikanz des radiologischen Nachweises von Rippenfrakturen im Rahmen von Bagatelltraumata}

Authors

Affiliations
P. Hoffstetter ${ }^{1,3}$, C. Dornia ${ }^{1,3}$, M. Wagner ${ }^{3}$, M. H. Al Suwaidi' ${ }^{2}$, C. Niessen ${ }^{3}$, L. M. Dendl ${ }^{3}$, C. Stroszczynski ${ }^{3}$, A. G. Schreyer $^{3}$

Radiology, Asklepios Medical Center Bad Abbach

Rheumatology/Clinical Immonology, Asklepios Medical Center, Bad Abbach

Radiology, University Medical Center Regensburg

Key words
ribs
thorax
conventional radiography
CT
trauma

received $\quad 15.8 .2013$ accepted $\quad 10.12 .2013$

\section{Bibliography}

DOI http://dx.doi.org/ 10.1055/s-0033-1356383 Published online: 19.3.2014 Fortschr Röntgenstr 2014; 186: 876-880 @ Georg Thieme Verlag KG Stuttgart · New York . ISSN 1438-9029

\author{
Correspondence \\ Christoph Niessen \\ Radiology, University Medical \\ Center Regensburg \\ Franz-Josef-Strauß-Allee 11 \\ 93053 Regensburg \\ Germany \\ Tel.: ++ 49/0941/9447401 \\ Fax: ++49/0941/9447402 \\ christoph.niessen@ukr.de
}

\section{Zusammenfassung}

$\nabla$

Hintergrund: Hemithoraxaufnahmen (HT) sind eine spezielle radiografische Technik zur Darstellung der knöchernen Anteile der Thoraxwand. Die Technik findet häufig Anwendung in der Evaluation von Bagatelltraumen des Thorax, oft in Kombination mit Thoraxübersichtsaufnahmen (THÜ). Ziel dieser Studie war es, die klinische Relevanz des radiologischen Nachweis von Rippenfrakturen im Rahmen von Bagatelltraumen zu evaluieren.

Methoden: Retrospektive Studie mit 669 Patienten, die eine HT erhielten, davon 405 eine zusätzliche THÜ. Die Befundberichte wurden hinsichtlich Frakturnachweis und -Ausschluss kategorisiert. Alle untersuchten Patienten wurden hinsichtlich ihres weiteren Therapieregimes in 4 Gruppen eingeteilt. Die Ergebnisse von HT und THÜ wurden mit dem McNemar-Test analysiert. Die Signifikanz zwischen den radiologischen Befunden und dem klinischen Verlauf wurde mit dem CHI-Quadrat- und Kruskal-Wallis-Test ermittelt.

Ergebnisse: 669 Patienten wurden eingeschlossen (61,4\% Männer, 38,6\% Frauen, Medianalter 51 Jahre, Spannweite 13 - 92 Jahre). In den Befunden der 669 HT wurden 157 (23,5\%) Patienten mit mindestens einer frakturierten Rippe identifiziert, bei 512 (76,5\%) ergab sich kein Frakturnachweis. Von den 157 Patienten mit Frakturen hatten $73(46,8 \%)$ eine solitäre, 38 (24,4\%) zwei und $45(28,8 \%)$ mehr als zwei frakturierte Rippen. In den 405 THÜ wurden in 69 (17\%) Fällen Frakturen nachgewiesen, in den korrespondierenden HT ergaben sich 87 (21,5\%) Frakturnachweise $(p<0,05)$. Der Anteil der Patienten mit Therapie betrug bei positivem Frakturnachweis $63,1 \%$, bei negativem Nachweis 64,5\% ( $p=0,25)$.

Schlussfolgerung: Unsere Ergebnisse deuten auf eine geringe klinische Relevanz von diagnostizierten Rippenfrakturen mit HT. Obwohl sie signifikant mehr Frakturen als THÜ nachweisen, scheint

\section{Abstract \\ $\nabla$}

Background: Conventional rib series (RS) represent a dedicated radiographic technique to visualize the bony parts of the chest wall. The method is commonly used to evaluate minor thoracic trauma, frequently in combination with chest radiographs (CRs). The aim of this study is to asses the clinical relevance of rib fractures diagnosed by RS in minor thoracic trauma.

Methods: Retrospective study of 669 patients who received RS for the evaluation of minor thoracic trauma. 405 of the 669 patients received an additional CR. Radiological reports were classified into fracture versus no fracture. Patients were divided into four groups depending on the clinical follow-up. The findings of RS and CR were analyzed using the McNemar test. The statistical significance between the results of the radiographic examinations and the clinical follow-up was analyzed by the Chi-Square test and the Kruskal-Wallis test.

Results: We included 669 patients $(61.4 \%$ men, $38.6 \%$ women, median age: 51 years, range: 13 - 92 years). Analyzing the reports of 669 patients who received RS, 157 (23.5\%) patients were diagnosed with at least one fractured rib while no fracture was found in 512 (76.5\%) patients. Considering the 157 patients with fractured ribs, 73 (46.8\%) had a single fracture, 38 (24.4\%) and two fractures and $45(28.8 \%)$ had more than two fractures. When assessing the 405 CRs, we detected 69 (17\%) fractures while the corresponding RS of the same patients revealed $87(21.5 \%)$ fractures $(p<0.05)$. Concerning all patients with rib fractures, $63.1 \%$ received medical therapy, while $64.5 \%$ of those patients without a radiologically documented fracture also received therapy $(\mathrm{p}=0.25)$.

Conclusion: Our results suggest a limited clinical value of detected rib fractures based on RS. Despite being superior compared to $\mathrm{CR}$ in diagnos- 
ihr Ergebnis keinen signifikanten Einfluss auf die therapeutische Entscheidungsfindung zu haben. Bagatelltraumen des Thorax sollten mit THÜ evaluiert werden, um frakturbegleitende Komplikationen wie Pneumo- oder Hämatothorax auszuschließen.

Kernaussagen:

- HT werden häufig bei thorakalen Bagatelltraumen durchgeführt.

- HT sind sensitiver zum Frakturnachweis als THÜ.

- Die Untersuchungsergebnisse haben jedoch wenig therapeutische Relevanz.

- THÜ sollten vorgezogen werden um frakturbegleitende Komplikationen auszuschließen. ing rib fractures, the results from RS seem to have no significant influence on further clinical management and therapeutic measures. Minor thoracic trauma should be evaluated by CR to exclude fracture-associated complications such as hemo- and pneumothorax.

Key Points:

- RS are commonly used in minor thorax trauma.

- RS reveals more rib fractures than CR.

- The results have low clinical significance.

- CR should be preferred to rule out fracture associated complications.

Citation Format:

- Hoffstetter P, Dornia C, Wagner M et al. Clinical Significance of Conventional Rib Series in Patients with Minor Thoracic Trauma. Fortschr Röntgenstr 2014; 186: 876-880

\section{Introduction}

Conventional rib series (RS) are a very common routinely performed radiological examination. It entails applying a dedicated radiographic technique to visualize and assess the bony parts of the chest wall by one or more oblique views, with or without marking the points of maximum tenderness. In comparison to routine chest radiographs (CRs), RS is carried out using lower Xray energy and a smaller field of view to optimize the contrast of the ribs. Both diagnostic modalities are common, RS alone or in combination with $\mathrm{CR}$. Severe thoracic trauma is regularly assessed by multidetector computed tomography (MDCT). However, minor blunt traumas are often examined by rib series [1-4]. The diagnostic yield of RS in evaluating thoracic injury is considered to be low compared with MDCT [5 - 7]. Because of the lower $\mathrm{X}$-ray energy, RS exposes the patient to a higher radiation dose than CR. The clinical value of RS is not clear. Minor thoracic trauma often results in nothing more than isolated rib fractures without any dislocation. In these cases RS might provide insufficient diagnostic accuracy, as non-dislocated rib fractures cannot always be detected. On the other hand, non-dislocated rib fractures are generally treated conservatively and very seldom have significant clinical sequelae.

The purpose of this study was to reveal the clinical significance of rib series in patients with minor thoracic trauma in a tertiary care university medical center.

\section{Materials and Methods}

\section{Patient data}

Based on a retrospective chart review we analyzed all patients who underwent a conventional radiographic examination by rib series in our tertiary care university medical center in a two-year period between 2008 and 2010. Out of a total of 767 examinations, we identified 669 patients fulfilling the following criteria: the indication for examination must be minor blunt thoracic trauma, and the clinical follow-up must be documented in the patient's chart.

Based on the original radiological reports, the findings were classified according to the presence or absence of rib fractures. The number and location of the involved ribs were documented. Additionally associated complications such as hemo- and pneumothorax were evaluated. The CRs of 405 of the 669 abovementioned patients were further assessed by two experienced board certified consultants to compare the diagnostic accuracy of both techniques.

For further analysis of the clinical follow-up of the patients, all available medical reports were assessed. Patients were followed up after undergoing rib series examinations and classified into the following four categories: (1) no special treatment, (2) pain therapy/requiring analgesia, (3) pain therapy and follow-up imaging and (4) requiring hospital admission and/or immediately further diagnostic workup.

\section{Radiographic techniques}

All patients were examined on a digital radiological workstation (Axiom Aristos Multix FDX, Software VB21B, Siemens Healthcare ${ }^{\circledR}$, Erlangen, Germany) with $70 \mathrm{kV}$ X-ray energy. Two oblique rib series were performed as grid radiography ( $\mathrm{Pb} 15 / 80$ ) for all patients with a focus distance of $150 \mathrm{~cm}$. The patients were examined in a standing position. Image interpretation was performed as soft reading on a digital diagnostic workstation (Syngo Imaging Advanced, Software Version VB36A, Siemens Healthcare ${ }^{\circledR}$, Erlangen, Germany) using two high-performance LCD monitors (Radioforce GS 220, Eizo ${ }^{\circledR}$, Mönchengladbach, Germany). Chest radiograph examinations were also performed as grid radiography (Pb15/80) in a standing position on the same digital workstation using 120 kV X-ray energy.

\section{Statistics}

WinSTAT ${ }^{\circledR}$ for Microsoft ${ }^{\circledR}$ Excel (R. Fitch Software ${ }^{\circledR}$, Bad Krotzingen, Germany) was used for all statistic calculations. The findings of the rib series and chest radiographs were analyzed using the McNemar test. The statistical significance between the results of the radiographic examinations and the clinical follow-up was analyzed by the Chi-Square test and the Kruskal-Wallis test. P-values of $<0.05$ were considered statistically significant.

\section{Ethics}

In accordance with the local ethics committee and due to the retrospective nature of this study, institutional review board approval was not necessary.

\section{Results}

669 patients were included ( $61.4 \%$ men, $38.6 \%$ women). The mean age was 51 years (range 13 - 92 years). Considering the initial examination reports of 669 rib series performed by residents (radiol- 


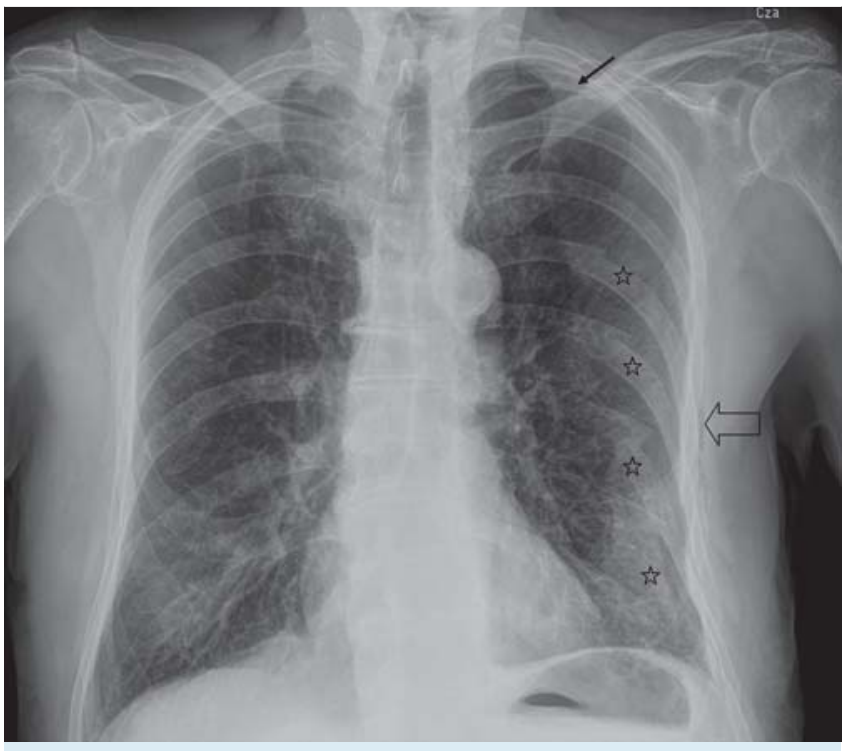

Fig. 1 64-year-old patient with fracture of the ribs VI-IX (ఓ⿱丶万) ), apical pneumothorax $(\rightarrow)$ and soft tissue emphysema $(\Rightarrow)$.

Abb. 1 64-jähriger Patient mit Frakturen der Rippen VU-IX ( $\succsim)$, apikalem Pneumothorax $(\rightarrow)$ und Weichteilemphysem $(\Rightarrow)$.

Table 1 Findings of rib series of 669 patients.

Tab. 1 Befunde der Hemithoraxaufnahmen von 699 Patienten.

\begin{tabular}{|lll|}
\hline no. of fractured ribs & \multicolumn{2}{l}{ no. of patients diagnosed by rib series } \\
\hline 0 & $512(76.5 \%)$ & \\
\hline 1 & 73 & total 157 \\
\hline 2 & 38 & $(23.5 \%)$ \\
\hline$>3$ & 45 & \\
\hline
\end{tabular}

Table 2 Findings of chest radiographs and rib series of 405 patients.

Tab. 2 Befunde der Thorax-und Hemithoraxaufnahmen von 405 Patienten.

\begin{tabular}{lllcc}
$\mathbf{P}=\mathbf{0 . 0 0 1}$ & \multicolumn{3}{c}{ rib series } \\
\cline { 3 - 5 } \begin{tabular}{l} 
McNemar \\
\cline { 3 - 5 } Chest radiograph
\end{tabular} & & fracture & no fracture & total \\
\cline { 3 - 5 } & fracture & 69 & 0 & 69 \\
\cline { 2 - 5 } & no fracture & 18 & 318 & 336 \\
\cline { 2 - 5 } & total & 87 & 318 & 405
\end{tabular}

ogy work experience ranging between 1 and 3 years) under the supervision of a board certified consultant, 157 (23.5\%) patients were diagnosed with at least one fractured rib, while no rib fracture was found in 512 (76.5\%) patients. Of the 157 patients with proven fractures, 73 (46.8\%) had a single rib fracture, 38 (24.4\%) had two broken ribs and 45 (28.8\%) had more than two broken ribs ( $\bullet$ Table 1 ). Pneumothorax and hemothorax were diagnosed in 7 and 5 cases respectively of the patients with rib fractures ( $\bullet$ Fig. 1). These 12 patients received both CR and RS. In 6 patients the complications were missed on the RS.

405 patients received additional CR, and 69 (17.0\%) of these cases were diagnosed with rib fractures. Comparing the corresponding rib series of these patients, 87 (21.5\%) patients with fractures could be identified ( $\bullet$ Fig. 2,3 ). None of the positive findings of a

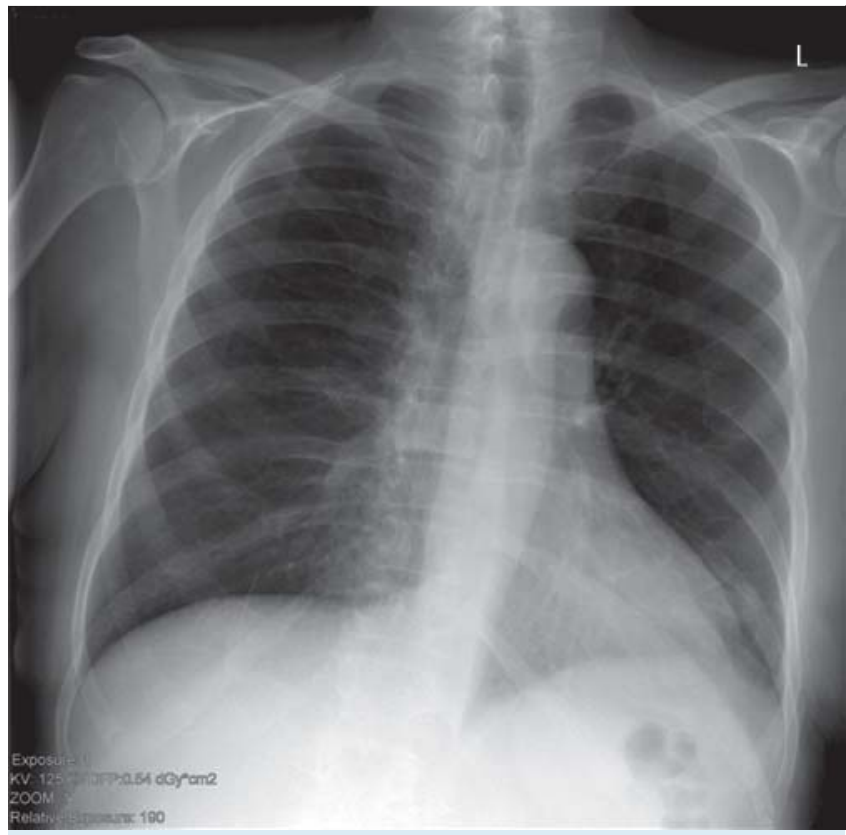

Fig. 2 46-year-old patient with minor blunt trauma to the thorax with an unremarkable chest radiograph.

Abb. 2 46-jähriger Patient mit Bagatelltrauma des Thorax und unauffälliger Thoraxübersichtsaufnahme.

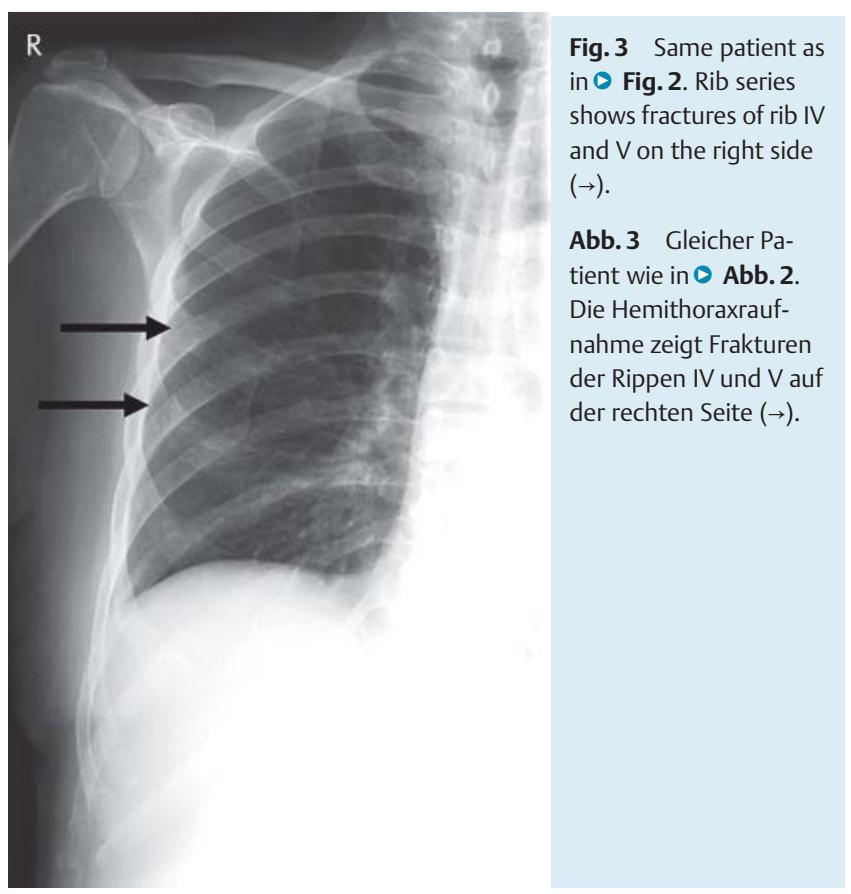

Fig. 3 Same patient as shows fractures of rib IV and $\mathrm{V}$ on the right side $(\rightarrow)$.

Abb. 3 Gleicher Panahme zeigt Frakturen der Rippen IV und $\mathrm{V}$ auf der rechten Seite $(\rightarrow)$.

fracture in CR were negative in the RS. These differences in the findings of CR and RS were significant ( $\bullet$ Table 2). This was further confirmed by the second reading that was carried out by the two experienced consultants. In addition to the findings above, a total of $18 \mathrm{rib}$ fractures, 8 in the CR group and 10 in the RS group, were newly diagnosed. In 112 (16.7\%) patients the findings of the RS and $\mathrm{CR}$ were only documented in the radiology report but not in the patient's chart. 
Table 3 Therapeutic sequelae of rib series of 669 patients.

Tab. 3 Therapeutische Relevanz der Befunde der Hemithoraxaufnahmen von 669 Patienten.

\begin{tabular}{|c|c|c|c|c|}
\hline \multirow{2}{*}{$\begin{array}{l}\mathrm{p}=0.25 \\
\text { Chi-Square }\end{array}$} & & \multicolumn{2}{|c|}{ therapeutic relevance } & \multirow[t]{2}{*}{ total } \\
\hline & & no treatment & treatment & \\
\hline \multirow[t]{3}{*}{ rib series } & no fracture & $182(35.5 \%)$ & $330(64.5 \%)$ & 512 \\
\hline & fracture & $58(36.9 \%)$ & $99(63.1 \%)$ & 157 \\
\hline & total & $240(35.9 \%)$ & $429(64.1 \%)$ & 669 \\
\hline
\end{tabular}

Table 4 Different medical interventions for radiographic findings in 429 patients.

Tab. 4 Therapeutische Konsequenzen in Abhängigkeit der radiologischen Befunde von 429 Patienten.

\begin{tabular}{|llllc|}
\hline $\mathbf{p}<0.001$ & Kruskal-Wallis & no fracture & fracture & total \\
\hline $\begin{array}{l}\text { level of } \\
\text { therapy }\end{array}$ & pain therapy & 329 & 66 & 395 \\
\cline { 2 - 4 } & $\begin{array}{l}\text { pain therapy } \\
\text { diagnostic follow-up }\end{array}$ & 1 & 15 & 16 \\
$\begin{array}{l}\text { pain therapy, immedi- } \\
\text { ate further diagnostic } \\
\text { workup and/or stat. } \\
\text { admission }\end{array}$ & 0 & 18 & 18 \\
\hline total & 330 & 99 & 429
\end{tabular}

Table 5 Confirmed fracture and specific treatment depending on the patient's age

Tab. 5 Frakturnachweis und spezifische Therapie in Abhängigkeit vom Patientenalter

\begin{tabular}{|llll|}
\hline age & no. of patients & fracture & treatment \\
\hline $45<$ & 255 & $60(23.5 \%)$ & $160(62.7 \%)$ \\
\hline $45-65$ & 237 & $58(24.4 \%)$ & $149(62.8 \%)$ \\
\hline$<65$ & 177 & $39(22.0 \%)$ & $120(67.7 \%)$ \\
\hline
\end{tabular}

Of all 669 patients, 429 patients received therapy. For the others no therapeutic procedures were documented in the charts. Of the 157 patients with proven rib fractures, $63.1 \%$ received therapy, and of those without a documented fracture $64.5 \%$ received therapy ( $\bullet$ Table 3 ).

Regarding the clinical significance of the radiographic examinations, there was no significant relationship with the finding of RS and the documented decision for or against treatment of the patient.

With $92 \%$ symptomatic pain therapy was the most common documented treatment. Follow-up by imaging or additional examinations was performed in $3.7 \%$ of the cases. Immediate further diagnostic workup or hospital admission was recommended for $4.3 \%$ of the treated patients ( $\bullet$ Table 4 ). There was a strong correlation between the positive finding of a fracture and the need for higher medical care. No relevant age-related differences were noted ( $\bullet$ Table 5). None of the evaluated patients required any kind of thoracic surgical intervention for their injuries.

\section{Discussion}

$\nabla$

Thoracic injury is the third most common type of trauma, following injuries of the head and the extremities [6]. Contrast-enhanced MDCT of the chest is considered to be the diagnostic method of choice for severe thoracic trauma. All relevant traumatic diagnoses can be made in a short time with high accuracy providing high sensitivity and specificity in the detection of pulmonary laceration, tracheobronchial injury, pneumothorax and aortic lesions [8].

Rib fractures represent the most common thoracic injury, and can be found in up to $67 \%$ of cases with blunt thorax trauma [9]. However, rib fractures may also occur without adequate trauma. Typical risk groups are elderly patients suffering from osteoporosis or those engaging in competitive sports $[10,11]$.

Fractures are the most common form of injury of the ribs. MDCT offers high diagnostic accuracy in evaluating the bony parts of the thorax [12]. Although the lower diagnostic sensitivity of radiography compared to MDCT is a known fact, radiography is known as the first line investigation in evaluating minor thorax traumas [1]. CR can depict bony injuries as well as typical complications of rib fractures such as pneumothorax and hemothorax. Former studies revealed a sensitivity for the detection of rib fractures by chest films of only $15-50 \%$ [13 - 15]. MDCT seems to be superior in evaluating chest wall injuries $[16,17]$.

The low sensitivity of chest radiography may be improved by using rib series with optimized bony contrast. De Lucca et al. examined 100 patients after thorax trauma with both techniques. Chest film revealed 13 patients with rib fracture while rib series detected 28 [13]. Our results also show that RS reveals more fractures than CR. To the best of our knowledge, there are no studies which evaluate the diagnostic accuracy of dedicated rib series in comparison with MDCT.

The clinical significance of the radiographic proof of a rib fracture in the case of minor thorax trauma is a common point of discussion between radiologists and referring physicians. Isolated fractures of the ribs without associated complications, even with an obvious dislocation of the fracture are treated symptomatically [18]. Our results show that the decision whether to treat or not seems to be independent from the results of the RS. This hypothesis could be supported by the fact that $16.7 \%$ of the results of the radiographic examination were not documented in the patient's chart. On the other hand, patients diagnosed with a rib fracture, who received further therapy, received more medical care, most probably due to the higher pain scores along with the associated complications such as developing a pneumothorax and/or a hemothorax.

The results of our study were comparable/similar to those obtained by a study of Davis et al. However, the number of patients examined was much smaller and no RS examinations were carried out [19].

Based on our investigation, the extra diagnostic yield provided by $\mathrm{RS}$ in comparison to CR was not found to be of additional clinical relevance. In some cases the exclusion of a fracture might be a matter of urgent necessity, for example for forensic reports or in cases of suspected child abuse [20]. For these special situations, where the detection of bony lesions plays an important role, one has to consider alternative imaging modalities. For example, MDCT provides higher diagnostic accuracy for bony injury and associated complications, even cartilage damage can be visualized [12]. An argument for using RS instead of MDCT might be the radiation dose. RS delivers about $1-1.5 \mathrm{mSv}$ of radiation dose, while modern low- 
dose MDCT protocols should reach comparable values [21]. At this point it is important to mention ultrasonography, which is a very helpful diagnostic tool for the detection of rib fractures. Due to its high spatial resolution, it may even be superior to MDCT. Griffith et al. revealed in their study of 50 patients a sensitivity of $90 \%$ for the detection of rib fractures, while radiography showed only a sensitivity of $15 \%$. The specificity of both modalities was $100 \%$ [14]. On the other hand, ultrasonography has known limitations such as high examiner and patient dependence, and missing standards to perform and document the examinations. MRI may also represent a helpful tool in evaluating traumatic bony injuries of the chest wall, but no data has been published so far, and the lower spatial resolution might be a problem. The restricted availability is probably the most limiting factor for its use in the diagnostic workup of emergency patients.

MDCT is the method of choice for detecting rib fractures because it simultaneously provides a higher diagnostic yield while delivering an acceptable radiation dose [17]. However, if in cases of minor thorax trauma a rib fracture has no impact on the therapeutic procedure, a CR to rule out complications might be enough especially because of the lower radiation dose.

Although our study includes a high number of patients, we are of course aware of its limitations. Due to the retrospective character, there is no defined standard for documenting the follow-up of the patients. The grade of information given in the medical reports shows a wide variety and a lot of the reports were not very detailed. Therefore, it was only possible to classify three categories of therapy. Probably some therapeutic procedures and further diagnostic workup were not documented in the charts. For example respiratory care exercises/physiotherapy to avoid pneumonias are a common supportive therapy [18], but on the other hand the risk of developing these complication seems to be low [22]. 70 of the 157 patients with proven fractures in the RS did not receive an additional CR. The reasons for this were not clear. Another bias might be the fact that in many of the patients, who received RS and CR, both examinations were performed as one complete procedure. This may have caused reduced attention to bony lesions in the interpretation of the CR with consecutive significantly higher sensitivity for the detection of rib fractures in the RS.

\section{Conclusion}

\section{$\nabla$}

Our results suggest that RS for detecting rib fractures in patients with minor thoracic trauma is of limited clinical value. Despite being superior to $C R$ in diagnosing rib fractures, the results from RS seem to have no significant influence on further clinical management and therapeutic measures. Blunt minor thorax trauma should be evaluated by CR to rule out dislocated fractures and associated complications such as hemothorax and pneumothorax. If there is high clinical suspicion of rib fractures in the presence of normal CR findings, alternative imaging modalities should be performed.

\section{References}

1 Bhavnagri SJ, Mohammed TL. When and how to image a suspected broken rib. Cleve Clin J Med 2009; 76: 309-314

2 Heyer CM, Rduch GJ, Wick $M$ et al. Anwendung der 16-Zeilen-Mehrdetektor-CT in der Initialdiagnostik beim Polytrauma: Eine Zeitanalyse. Fortsch Röntgenstr 2005; 177: 1677-1682

3 Hoffstetter P, Herold T, Daneschnejad $M$ et al. Nicht traumaassozierte Nebenbefunde bei Ganzkörpercomputertomografien im Rahmen der Polytraumadiagnostik. Fortschr Röntgenstr 2008; 180: 120-126

4 Loupatatzis C, Schindera S, Gralla J et al. Whole-body computed tomography for multiple traumas using a triphasic injection protocol. Eur Radiol 2008; 18: 1206-1214

5 Exadaktylos AK, Duwe J, Eckstein $F$ et al. The role of contrast-enhanced spiral CT imaging versus chest X-rays in surgical therapeutic concepts and thoracic aortic injury: a 29-year Swiss retrospective analysis of aortic surgery. Cardiovasc J S Afr 2005; 16: 162 - 165

6 Oikonomou A, Prassopoulos P. CT imaging of blunt chest trauma. Insights Imaging 2011; 2: $281-295$

7 Van Hise ML, Primack SL, Israel RS et al. CT in blunt chest trauma: indications and limitations. Radiographics 1998; 18: 1071-1084

8 O'Connor JV, Adamski J. The diagnosis and treatment of non-cardiac thoracic trauma. J R Army Med Corps 2010; 156: 5-14

9 Bergeron E, Lavoie A, Clas D et al. Elderly trauma patients with rib fractures are at greater risk of death and pneumonia. J Trauma 2003; 54: $478-485$

10 McDonnell LK, Hume PA, Nolte V. Rib stress fractures among rowers: definition, epidemiology, mechanisms, risk factors and effectiveness of injury prevention strategies. Sports Med 2011; 41: 883-901

11 Wuermser LA, Achenbach SJ, Shreyasee A et al. What accounts for rib fractures in older adults? J Osteoporos 2011; 2011: 457591

12 Levine BD, Motamedi K, Chow K et al. CT of rib lesions. Am J Roentgenol Am J Roentgenol 2009; 193: 5-13

13 DeLuca SA, Rhea JT, O'Malley TO. Radiographic evaluation of rib fractures. Am J Roentgenol Am J Roentgenol 1982; 138: 91 -92

14 Griffith JF, Rainer TH, Ching AS et al. Sonography compared with radiography in revealing acute rib fracture. Am J Roentgenol Am J Roentgenol 1999; 173: $1603-1609$

15 Hong TS, Reyes JA, Moineddin R et al. Value of postmortem thoracic CT over radiography in imaging of pediatric rib fractures. Pediatr Radiol 2011; 41: 736-748

16 Wootton-Gorges SL, Stein-Wexler R, Walton JW et al. Comparison of computed tomography and chest radiography in the detection of rib fractures in abused infants. Child Abuse Negl 2008; 32: 659-663

17 Traub M, Stevenson M, McEvoy $S$ et al. The use of chest computed tomography versus chest X-ray in patients with major blunt trauma. Injury-International Journal of the Care of the Injured 2007; 38: 43-47

18 Karadayi S, Nadir A, Sahin E et al. An analysis of 214 cases of rib fractures. Clinics (Sao Paulo) 2011; 66: 449-451

19 Davis S, Affatato A. Blunt chest trauma: utility of radiological evaluation and effect on treatment patterns. American Journal of Emergency Medicine 2006; 24: $482-486$

20 Bennett BL, Chua MS, Care $M$ et al. Retrospective review to determine the utility of follow-up skeletal surveys in child abuse evaluations when the initial skeletal survey is normal. BMC Res Notes 2011; 4: 354

21 Larke FJ, Kruger RL, Cagnon CH et al. Estimated radiation dose associated with low-dose chest CT of average-size participants in the National Lung Screening Trial. Am J Roentgenol Am J Roentgenol 2011; 197: $1165-1169$

22 Chauny JM, Emond M, Plourde $M$ et al. Patients with rib fractures do not develop delayed pneumonia: a prospective, multicenter cohort study of minor thoracic injury. Ann Emerg Med 2012; 60: 726-731 